\title{
Validation by RQ-PCR and flow cytometry of a-defensin1-3 (DEFA1-3) overexpression in relapsed and refractory acute lymphoblastic leukemia
}

\author{
GEERTRUY TE KRONNIE ${ }^{1}$, SILVIO BICCIATO ${ }^{2}$, LISA FRANCESCHINI ${ }^{1}$, BENEDETTA ACCORDI ${ }^{1}$, \\ MARTA CAMPO DELLÍORTO ${ }^{1}$, ANDREA RINALDI $^{1}$, ANDREA PESSION $^{3}$, ELENA BARISONE ${ }^{4}$, \\ VALENTINO CONTER ${ }^{5}$, FRANCO LOCATELLI ${ }^{6}$ and GIUSEPPE BASSO ${ }^{1}$ \\ ${ }^{1}$ Department of Pediatrics, University of Padova, via Giustiniani 3, I-35128 Padova; \\ ${ }^{2}$ Department of Chemical Process Engineering, University of Padova, via Marzolo 9, I-35131 Padova; \\ ${ }^{3}$ Department of Pediatrics, University of Bologna, Via Massarenti 11, I-40100 Bologna; ${ }^{4}$ Department of Pediatrics, \\ University of Turin, P.zza Polonia 6, I-10126 Turin; ${ }^{5}$ Department of Pediatrics, San Gerardo Hospital, Monza; \\ ${ }^{6}$ Pediatric Haematology and Oncology, IRCCS Policlinico San Matteo, Pavia, Italy
}

Received July 26, 2005; Accepted September 20, 2005

\begin{abstract}
In spite of high cure rates and improved overall survival, $25 \%$ of pediatric patients with acute lymphoblastic leukemia (ALL) relapse after obtaining complete remission. Additionally a small proportion of patients are refractory and do not attain remission. Microarray expression analysis of matched diagnosis-relapse B-lineage ALL sample pairs identified DEFAl-3 as a potential marker of relapse. Here, validation of $D E F A 1-3$ as a marker for therapy resistance is explored. DEFA1-3 expression was analysed by RQ-PCR in patient paired samples at diagnosis and relapse of 6 earlyrelapse (within 18 months) and 8 late-relapse (beyond 18 months) B-lineage ALL. Diagnostic samples of 19 patients with ALL who are in continuous complete remission (median time from diagnosis 47 month) and diagnostic samples of 5 refractory patients who had not achieved remission at day 35 of therapy were also analyzed. In addition, overexpression of $\alpha$-defensin 1-3 proteins in blast cells at relapse was analysed by flow cytometry. DEFA1-3 was overexpressed at relapse as compared to diagnosis in 12 of 14 samples. At diagnosis, the expression of DEFA1-3 was significantly higher in samples from refractory patients as compared to those of patients who are in CR and to those of patients who experienced late relapse. At diagnosis, patients who relapsed early after diagnosis could not be distinguished from refractory patients based on DEFA1-3 expression levels. Results suggest that high levels of DEFA1-3 mRNA and $\alpha$-defensin 1-3 protein expression are
\end{abstract}

Correspondence to: Dr Truus te Kronnie, Department of Pediatrics, University of Padova, via Giustiniani 3, I-35128 Padova, Italy E-mail: truustekronnie@unipd.it

Key words: B-lineage acute lymphoblastic leukemia, relapse, drug resistance, microarray, expression profiling, DEFA1-3 correlated with disease progression and failure of adequate response to conventional chemotherapy.

\section{Introduction}

In spite of high cure rates and improved overall survival, 25\% of pediatric patients with acute lymphoblastic leukemia (ALL) relapse after short or long durations of complete remission (CR) (1). The mechanisms underlying the clonal evolution toward relapse and the development of drug resistance are still poorly understood. Indeed, no relevant genotypic or phenotypic differences between blast cells collected at diagnosis and at relapse have been demonstrated (2) and, most likely, only small genetic alterations are implicated in the evolution toward relapse.

To identify aberrations specific of relapse that may be considered markers of disease progression, we chose to apply high throughput microarray gene expression to the identification of genes that change expression between diagnosis and relapse. We chose a longitudinal design for the microarray expression analysis, comparing expression in clonally identical, matched diagnosis and relapse samples of the same patient. High throughput microarray expression analysis in matched diagnosis-relapse sample pairs of patients with B-lineage ALL allows to eliminate every possible bias connected with interindividual variability in expression profiles of human subjects and between B-lineage ALL subtypes, and can identify new potential markers of relapsed leukemia. DEFA1-3, one of the genes encoding $\alpha$-defensins, which are part of a family of anti-microbial peptides, is one of the genes that was constantly overexpressed at relapse as compared to diagnosis in matched patient samples. Although the primary role of human defensin peptides has been implicated in the innate response towards microbial invasion, evidence points to a more versatile function; defensins are now known to play also a role in antigen driven immune response $(3,4)$ and in anti-tumour immunity $(5)$. It has been also suggested that these peptides play a role as 
Table I. Patient characteristics.

\begin{tabular}{|c|c|c|c|c|c|c|}
\hline Patient no. & Sex & $\begin{array}{c}\text { Age at } \\
\text { diagnosis } \\
\text { (months) }\end{array}$ & Phenotype & Treatment protocol & $\begin{array}{c}\text { Molecular } \\
\text { translocation } \\
\text { (MLL-AF4; } \\
\text { BCR-ABL) }\end{array}$ & $\begin{array}{l}\text { D/R interval } \\
\text { (months) }\end{array}$ \\
\hline \multicolumn{7}{|c|}{$\begin{array}{l}\text { Early-relapse } \\
\text { patients }\end{array}$} \\
\hline 6 & $\mathrm{M}$ & 7 & Prepre-B & 30 AIEOP LAL 9503 & MLL-AF4 & 5 \\
\hline 44 & M & 66 & Pre-B & 31 AIEOP LAL 2000 & Negative & 10 \\
\hline $31^{\mathrm{a}}$ & $\mathrm{F}$ & 131 & Pre-B & 31 AIEOP LAL 2000 & Negative & 11 \\
\hline 8 & $\mathrm{~F}$ & 60 & Pre-B & 29/30 AIEOP LAL9502 & Negative & 11 \\
\hline $32^{\mathrm{a}}$ & $\mathrm{F}$ & 9 & Pre-B & 29/30 AIEOP LAL9502 & Negative & 13 \\
\hline 5 & M & 5 & Common & 57 AIEOP LAL INTERFANT 99 & Negative & 15 \\
\hline \multicolumn{7}{|c|}{$\begin{array}{l}\text { Late-relapse } \\
\text { patients }\end{array}$} \\
\hline $53^{\mathrm{a}}$ & M & 10 & Pre-B & 57 AIEOP LAL INTERFANT 99 & Negative & 31 \\
\hline 43 & M & 88 & - & 29 AIEOP LAL9502 & Negative & 35 \\
\hline 7 & M & 55 & Common & 29 AIEOP LAL 9503 & Negative & 37 \\
\hline 3 & $\mathrm{~F}$ & 88 & Common & 25 AIEOP LAL9102 & Negative & 40 \\
\hline $65^{\mathrm{a}}$ & M & 70 & Common & 29 AIEOP LAL9502 & Negative & 41 \\
\hline $52^{\mathrm{a}}$ & $\mathrm{M}$ & 53 & Common & 29 AIEOP LAL9502 & Negative & 44 \\
\hline 4 & M & 168 & Pre-B & 29 AIEOP LAL9502 & Negative & 56 \\
\hline $56^{\mathrm{a}}$ & M & 164 & Pre-B & 30 AIEOP LAL 9503 & Negative & 63 \\
\hline $54^{\mathrm{a}}$ & $\mathrm{F}$ & 133 & Pre-B & 29 AIEOP LAL9502 & Negative & 80 \\
\hline \multicolumn{7}{|c|}{$\begin{array}{l}\text { De novo resistant } \\
\text { patients }\end{array}$} \\
\hline 22 & M & 153 & Common & 26 AIEOP LAL 9103 & - & Resistant \\
\hline 23 & M & 108 & Pre-B & 30 AIEOP LAL 9503 & - & Resistant \\
\hline 24 & $\mathrm{~F}$ & 152 & Common & 31 AIEOP LAL 2000 & Negative & Resistant \\
\hline 25 & $\mathrm{M}$ & 183 & Common & 31 AIEOP LAL 2000 & Negative & Resistant \\
\hline 26 & M & 133 & Common & 31 AIEOP LAL 2000 & Negative & Resistant \\
\hline \multicolumn{7}{|c|}{ Patients in CR } \\
\hline 68 & $\mathrm{~F}$ & 144 & Common & 31 AIEOP LAL 2000 & Negative & $46 \mathrm{~m} \mathrm{CR}$ \\
\hline 69 & $\mathrm{~F}$ & 103 & Common & 29 AIEOP LAL 9502 & BCR-ABL & $94 \mathrm{~m} \mathrm{CR}$ \\
\hline 70 & M & 25 & Common & 31 AIEOP LAL 2000 & Negative & $47 \mathrm{~m} \mathrm{CR}$ \\
\hline 71 & M & 25 & Common & 31 AIEOP LAL 2000 & Negative & $38 \mathrm{~m} \mathrm{CR}$ \\
\hline 73 & $\mathrm{~F}$ & 10 & Prepre-B & - & MLL-AF4 & $41 \mathrm{~m} \mathrm{CR}$ \\
\hline 74 & $\mathrm{~F}$ & 1 & Prepre-B & 57 AIEOP LAL INTERFANT 99 & MLL-AF4 & $47 \mathrm{~m} \mathrm{CR}$ \\
\hline 75 & $\mathrm{~F}$ & 165 & Prepre-B & 31 AIEOP LAL 2000 & MLL-AF4 & $43 \mathrm{~m} \mathrm{CR}$ \\
\hline 76 & $\mathrm{~F}$ & 48 & Prepre-B & 31 AIEOP LAL 2000 & MLL-AF4 & $40 \mathrm{~m} \mathrm{CR}$ \\
\hline 77 & M & 32 & Common & 31 AIEOP LAL 2000 & Negative & $46 \mathrm{~m} \mathrm{CR}$ \\
\hline 79 & $\mathrm{~F}$ & 30 & - & 29 AIEOP LAL 9502 & Negative & 90m CR \\
\hline 80 & M & 75 & Pre-B & 31 AIEOP LAL 2000 & Negative & $345 \mathrm{~m} \mathrm{CR}$ \\
\hline 81 & M & 43 & Common & 29 AIEOP LAL 9502 & Negative & $100 \mathrm{~m} \mathrm{CR}$ \\
\hline 82 & M & 36 & Common & 29 AIEOP LAL 9502 & Negative & 93m CR \\
\hline 83 & $\mathrm{~F}$ & 60 & Common & 31 AIEOP LAL 2000 & Negative & $47 \mathrm{~m} \mathrm{CR}$ \\
\hline 84 & $\mathrm{~F}$ & 214 & Common & 29 AIEOP LAL 9502 & Negative & $102 \mathrm{~m} \mathrm{CR}$ \\
\hline 87 & $\mathrm{~F}$ & 96 & Pre-B & 31 AIEOP LAL 2000 & Negative & $40 \mathrm{~m} \mathrm{CR}$ \\
\hline 88 & M & 57 & Common & 29 AIEOP LAL 9502 & Negative & $84 \mathrm{~m} \mathrm{CR}$ \\
\hline 91 & $\mathrm{~F}$ & 84 & Common & 29 AIEOP LAL 9502 & Negative & $105 \mathrm{~m} \mathrm{CR}$ \\
\hline 92 & M & 42 & Pre-B & 31 AIEOP LAL 2000 & Negative & $42 \mathrm{~m} \mathrm{CR}$ \\
\hline
\end{tabular}

CR, complete remission; D, diagnosis; R, relapse; Pre-B, Pre-B ALL; Pre-Pre-B, Pre-Pre-B ALL; Common, Common ALL; For phenotypic

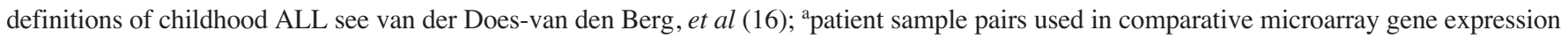
analysis. 
transcription factors (6). Overexpression of DEFAl-3 might be related to the increased malignancy of relapsed leukaemia and be predictive of therapy resistance at relapse.

In order to validate the observed overexpression of DEFA1-3 at relapse, the expression of DEFA1-3 was analysed by RQ-PCR in sample pairs of 14 patients with relapsed Blineage ALL. Additionally, the expression of DEFA1-3 was analysed in 19 samples of patients maintaining a state of continuous complete remission and in samples of 5 patients with refractory ALL who did not obtain CR by day 35 after the start of treatment.

We additionally validated the expression of $\alpha$-defensin 1-3 in leukemic blast cells by flow cytometry using a specific monoclonal antibody (mAb) for HNP1-3. We demonstrated that $\alpha$-defensin $1-3$ is indeed expressed by leukemic blast cells and that, in pair-wise blast cell comparison, $\alpha$-defensin 1-3 expression is higher at relapse as compared with samples at diagnosis for the same patients.

\section{Materials and methods}

Patient characteristics. Patient information pertinent to this study is reported in Table I. The ALL scientific committee of AIEOP (Italian Association for Pediatric Hematology and Oncology) approved the study protocol. Phenotypic characterization of patients had been performed by flow cytometry using a direct immunofluorescence technique with four-color combinations of mAbs (7). The panel of monitored markers is the one routinely employed for diagnosis of B-lineage ALL at the AIEOP reference laboratory for immunophenotypic studies at the University of Padova. Specific genetic aberrations (AF4-MLL and BCR-ABL) have been identified through molecular studies (i.e. RT-PCR assays) according to the BIOMED-1 protocol (8). For all patients studied at diagnosis and relapse, the clonality profile of the blast cells was demonstrated to be unchanged (9).

Microarray analysis. We used a total of $10-20 \times 10^{6}$ cells to obtain RNA using the Trizol (Invitrogen) purification method, according to the manufacturer's instructions. This generally yielded 8-10 $\mu \mathrm{g}$ of total RNA. Labelling was performed using the CyScribe First Strand cDNA Labelling Kit (Amersham Bio-sciences, CA, USA) according to the manufacturer's instructions; total RNA samples at diagnosis were labeled using Cy3 dUTP (Amersham Biosciences), and total RNA samples at relapse were labeled using Cy5 dUTP (Amersham Biosciences). After reverse transcription, the templates were fragmented by addition of $2 \mu 1$ of $2.5 \mathrm{M} \mathrm{NaOH}$ and incubated at $37^{\circ} \mathrm{C}$ for $15 \mathrm{~min}$. The degradation reaction was stopped by addition of $10 \mu \mathrm{l}$ of $2 \mathrm{M}$ HEPES. After neutralization, labelled cDNA samples were cleaned using a Microcon centrifugal filter device (Millipore, Molsheim, France). Purified samples were concentrated to a volume of $10 \mu 1$ in a speed Vacufuge (Eppendorf, NY, USA) without heat and, for each sample pair (diagnosis and relapse from the same patient), the labeled Cy3 and Cy5 samples were combined and dissolved in $240 \mu 1$ salt-based hybridization buffer (MWG-Biotech Laboratories, Muenchen, Germany). Hybridization was performed according to the manufacturer's guidelines (MWG-Biotech Laboratories). Hybridization occurred overnight at $42^{\circ} \mathrm{C}$ using wet hybridization chambers (MWG-Biotech Laboratories). The following day arrays were washed for $5 \mathrm{~min}$ at room temperature in 2 X SSC $0.1 \%$ SDS, followed by 1 X SSC and, finally, in 0.1X SSC. Arrays were scanned using a ScanArray 4000 scanner with ScanArrayExpress software (Packard Bioscience Instruments, Billerica, MA, USA). Experimental details of microarray analysis, according to MIAME guidelines, and raw expression data can be found at Gene Expression Omnibus http://www.ncbi.nlm.nih.gov/geo/query/acc.cgi?acc= GPL292.

$R Q-P C R$ of DEFA1-3 expression. Total RNA of 6 out of 7 sample pairs of patients that were also used in the microarray experiments (pts no. 32, 53, 65, 52, 56 and 54 of Table II) together with 8 diagnosis/relapse sample pairs of additional patients (pts no. $6,44,8,5,43,7,3$ and 4 of Table II), and of 5 refractory patients and 19 patients in continuous complete remission were used as template for reverse transcription (RT)-PCR. The Superscript ${ }^{\mathrm{TM}}$ II RNAse H-reverse transcriptase kit (Invitrogen, Carlsbad, CA, USA) was used for $\mathrm{RT}$ using $1 \mu \mathrm{g}$ of total RNA and $1 \mu \mathrm{g}$ of random primers (Invitrogen). The RT product was aliquoted and stored at $-80^{\circ} \mathrm{C}$. Forward and reverse primers were designed using Applied Biosystem's Primer Express v1.0 ${ }^{\mathrm{TM}}$ software (Applied Biosystems, Foster City, CA, USA). The primers for DEFA1-3 are: F, TCT GGTCACCCTGCCTAGCT; and R, AGGAGAATGGCAG CAAGGA. The housekeeping gene, GUS, was used for normalization of DEFA1-3 expression. The primers for GUS are: F, GAAAATATGTGGTTGGAGAGCTCATT; and R, CCGAGTGAAGATCCCCTTTTTA. For RQ-PCR each reaction mix $(25 \mu \mathrm{l})$ contained $2 \mathrm{x} \mathrm{Sybr}^{\circledR}$ Green Master Mix, $50 \mu \mathrm{M}$ forward and reverse primers and approximately $5 \mathrm{ng}$ of total template. Cycle conditions for the ABI 7700 were $50^{\circ} \mathrm{C}$ for $2 \mathrm{~min}, 95^{\circ} \mathrm{C}$ for $10 \mathrm{~min}, 95^{\circ} \mathrm{C}$ for $15 \mathrm{sec}$ and $60^{\circ} \mathrm{C}$ for $1 \mathrm{~min}$, for a total of 40 cycles.

All patient samples were analyzed in triplicate in parallel with a series of 5 dilutions (in triplicate) of standard cDNA reverse transcribed from RNA of mononuclear cells from healthy bone marrow donors. The relative quantity of the specific mRNA (DEFAl-3 and GUS) for each sample was calculated based on mean $\mathrm{Ct}$ values and, with the corresponding standard curve, the estimated input amount was calculated by linear regression.

Flow cytometry. To independently assess $\alpha$-defensin 1-3 expression in blast cells of ALL patients at diagnosis and relapse, $\alpha$-defensin 1-3 protein expression was monitored by flow cytometry using a $\alpha$-defensin $1-3$ specific mAb. For this purpose, mononuclear cells from bone marrow samples were isolated using a Lymphoprep ${ }^{\mathrm{TM}}$ density gradient $(1.077 \mathrm{~g} / \mathrm{ml}$; Nycomed Pharma, Oslo, Norway), as recommended by the manufacturer (10). Cells were re-suspended in FACS Buffer [ $1 \%$ fetal calf serum and $0.1 \%$ sodium azide in phosphatebuffered saline (PBS)] at a concentration range of $2.5 \times 10^{5}$ and $7.5 \times 10^{5}$ cells per test.

For intracellular staining, cells were fixed then permeabilized and incubated with $10 \mu \mathrm{g} / \mathrm{ml} \alpha$-defensin purified $\mathrm{IgG}$ $\mathrm{mAb}$, specific for $\alpha$-defensin1-3 (Biogenesis Ltd., Poole, UK) (11) for $15 \mathrm{~min}$ at room temperature, washed twice with FACS Buffer and stained with FITC-conjugated AffinityPure F(ab')2 
Table II. Real-time comparative quantitative PCR (RQ-PCR).

\begin{tabular}{|c|c|c|c|c|c|c|c|c|c|c|c|}
\hline \multirow[b]{3}{*}{ Patient no. } & \multicolumn{5}{|c|}{ Diagnosis } & \multicolumn{5}{|c|}{ Relapse } & \multirow[b]{3}{*}{$\begin{array}{l}\mathrm{R} / \mathrm{D} \\
\text { ratio }\end{array}$} \\
\hline & \multicolumn{2}{|r|}{$\mathrm{Ct}$} & \multicolumn{3}{|c|}{ Input } & \multicolumn{2}{|r|}{$\mathrm{Ct}$} & \multicolumn{3}{|c|}{ Input } & \\
\hline & GUS & DEFAl-3 & $G U S$ & DEFAl-3 & $\begin{array}{c}\text { DEFAl-3/ } \\
\text { GUS }\end{array}$ & GUS & DEFAl-3 & $G U S$ & DEFAl-3 & $\begin{array}{c}D E F A l-3 / \\
\text { GUS }\end{array}$ & \\
\hline \multicolumn{12}{|l|}{$\begin{array}{l}\text { Early } \\
\text { relapse }\end{array}$} \\
\hline 6 & 19.61 & 17.21 & 6.49 & 20.68 & 3.19 & 19.17 & 14.8 & 8.66 & 129.87 & 14.99 & 4.71 \\
\hline 44 & 19.51 & 15.67 & 6.93 & 66.68 & 9.62 & 19.81 & 17.01 & 5.69 & 24.1 & 4.24 & 0.44 \\
\hline 8 & 17.88 & 17.14 & 20.2 & 17.42 & 0.86 & 18.51 & 17.79 & 13.42 & 10.84 & 0.81 & 0.94 \\
\hline 32 & 22.89 & 19.86 & 0.76 & 2.08 & 2.74 & 22.52 & 18.8 & 0.98 & 4.22 & 4.32 & 1.58 \\
\hline 5 & 19.92 & 17.36 & 5.3 & 18.35 & 3.47 & 19.02 & 15.78 & 9.55 & 61.46 & 6.43 & 1.86 \\
\hline \multicolumn{12}{|l|}{$\begin{array}{l}\text { Late } \\
\text { relapse }\end{array}$} \\
\hline 53 & 26.91 & 29.28 & 0.02 & 0 & 0.04 & 22.2 & 18.43 & 0.6 & 1.23 & 2.06 & 57.86 \\
\hline 43 & 31.4 & 33.77 & 0 & 0 & 0.04 & 18.44 & 15.88 & 14.02 & 43.12 & 3.08 & 87.47 \\
\hline 7 & 23.22 & 19.98 & 0.62 & 2.5 & 4.04 & 19.8 & 18.67 & 5.73 & 6.79 & 1.19 & 0.29 \\
\hline 3 & 19.26 & 21.05 & 8.19 & 1.03 & 0.13 & 21.28 & 18.7 & 2.2 & 5.63 & 2.56 & 20.34 \\
\hline 65 & 25.11 & 25.68 & 0.19 & 0.05 & 0.29 & 25.06 & 20.81 & 0.19 & 0.95 & 4.92 & 17.00 \\
\hline 52 & 23.21 & 17.82 & 0.61 & 8.07 & 13.22 & 23.76 & 16.47 & 0.51 & 19.89 & 38.77 & 2.93 \\
\hline 4 & 18.5 & 19.79 & 13.45 & 2.56 & 0.19 & 18.48 & 18.53 & 13.63 & 6.38 & 0.47 & 2.46 \\
\hline 56 & 26.42 & 29.15 & 0.08 & 0.01 & 0.09 & 26.62 & 20.94 & 0.07 & 0.88 & 12.36 & 141.96 \\
\hline 54 & 23.99 & 19.4 & 0.36 & 2.82 & 7.92 & 23.76 & 14.63 & 0.42 & 67.97 & 163.02 & 20.58 \\
\hline
\end{tabular}

De novo

resistance

$\begin{array}{llllcc}22 & 20.53 & 15.61 & 3.58 & 59.27 & 16.54 \\ 23 & 19.47 & 16.38 & 7.14 & 33.37 & 4.67 \\ 24 & 20.8 & 16.57 & 3 & 29.14 & 9.70 \\ 25 & 24.23 & 17.46 & 0.3 & 9.21 & 30.3 \\ 26 & 25.77 & 20.57 & 0.12 & 1.1 & 8.93\end{array}$

Continuous

complete

remission

$\begin{array}{lllllr}68 & 22.38 & 20.94 & 1.07 & 0.86 & 0.81 \\ 69 & 23.94 & 19.32 & 0.4 & 2.18 & 5.51 \\ 70 & 22.06 & 19.82 & 1.31 & 1.63 & 1.24 \\ 71 & 23.24 & 23.23 & 0.62 & 0.23 & 0.37 \\ 73 & 22.36 & 18.12 & 1.09 & 4.32 & 3.98 \\ 74 & 23.19 & 35.78 & 0.64 & 0 & 0.04 \\ 75 & 22.19 & 22.68 & 1.21 & 0.32 & 0.26 \\ 76 & 25.37 & 25.22 & 0.16 & 0.07 & 0.46 \\ 77 & 23.2 & 23.68 & 0.63 & 0.18 & 0.28 \\ 79 & 24.86 & 19.24 & 0.22 & 2.28 & 10.39 \\ 80 & 22.29 & 19.37 & 1.13 & 2.11 & 1.86 \\ 81 & 26.51 & 23.17 & 0.07 & 0.24 & 3.58 \\ 82 & 22.67 & 21.42 & 0.88 & 0.65 & 0.74 \\ 83 & 24.1 & 19.24 & 0.34 & 2.22 & 6.54 \\ 84 & 25.82 & 19.23 & 0.11 & 2.23 & 20.9 \\ 87 & 22.2 & 20.7 & 1.21 & 0.97 & 0.81 \\ 88 & 40 & 40 & 0 & 0 & 2.21 \\ 91 & 24.07 & 20.51 & 0.34 & 1.08 & 3.14 \\ 92 & 23.42 & 16.19 & 0.54 & 12.5 & 23.35\end{array}$

All samples and series of 5 dilutions for standards have been analysed in triplicate. RNA for standards has been derived from bone marrow mononuclear cells of healthy donors The relative quantity of the specific mRNA (DEFA1-3 and GUS) for each sample was calculated based on mean Ct values and, with the corresponding standard curve, the estimated input amount was calculated by linear regression. DEFA1-3 was normalized for each patient sample using its relative GUS expression. Samples of patient no. 31 (Table I) were not analysed by RQ-PCR because material was unavailable. 


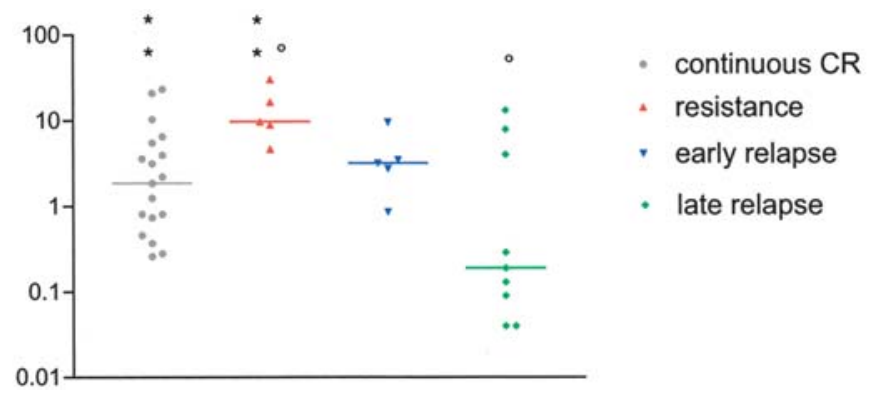

Figure 1. Scatter diagrams of normalized DEFA1-3 expression levels from RQ-PCR experiments (Table II). Data in logarithmic scale refer to samples taken at diagnosis in good therapy responders (patients maintaining continuous complete remission) and refractory patients (resistant to therapy) and in patients who had either early or late relapse. Bars indicate the median values for each group of patients. DEFA1-3 expression statistically discriminates refractory patients from control patients who are in continuous complete remission $\left({ }^{* *} \mathrm{p}=0.03\right)$ and from patients who experienced late relapse $\left({ }^{\circ} \mathrm{p}=0.03\right)$. In fact, expression levels in refractory patients are significantly higher than levels in control patients who are in continuous complete remission and also different from DEFA1-3 expression levels in late relapsed patients. DEFA1-3 expression does not discriminate between refractory patients and patients who had an early relapse.

Fragment goat anti-mouse IgG $(\mathrm{H}+\mathrm{L})(10 \mu \mathrm{g} / \mathrm{ml})$ (Immunotech, Marseille, France). Cells were then washed and incubated with $50 \mu \mathrm{g} / \mathrm{ml}$ unlabeled goat anti-mouse $\mathrm{F}\left(\mathrm{ab}^{\prime}\right) \mathrm{s}$ for $30 \mathrm{~min}$ at $4^{\circ} \mathrm{C}$, to block the remaining free binding sites. The cells were counter-labeled with CD45-ECD $(10 \mu \mathrm{g} / \mu \mathrm{l})$ (Immunotech) for immunological gating of the blast cell population. The association of side scatter (SS) with an immunological marker, such as CD45, was the preferred method for blast cell identification (CD45 expression in blast cells is typically lower than that of normal lymphocytes). Cells were analyzed on Epics-XL MCL (Beckman Coulter, Fullerton, CA, USA).

Statistical analysis. For statistical comparison of DEFA1-3 expression values between patient groups a non-parametric Wilcoxon signed rank test was used to calculate p-values.

\section{Results and discussion}

DEFA1-3 appeared constantly up-regulated at relapse as compared to diagnosis; in all 7 sample pairs, DEFA1-3 was largely overexpressed at relapse (expression ratios at relapse versus diagnosis $\geq 2$; average ratio of $24.27 \pm 30.71$ ). Although $\alpha$-defensin 1-3 is a marker of malignant cells, the gene is not commonly considered to be expressed in B-lymphocytes or leukemic blast cells. Thus, before considering it a diagnostic or disease-progression marker, we chose to analyse in more detail the DEFA1-3 expression in leukemic blast cell samples of patients with B-lineage ALL (Table I).

The expression levels of DEFA1-3 were validated by realtime comparative quantitative PCR (RQ-PCR) in 14 diagnosisrelapse sample pairs (Table I), including 6 of the patient sample pairs used in the microarray analysis. A higher expression at relapse (expression ratios $\geq 1.58$ at relapse versus diagnosis, last column, Table II) was confirmed in 12 of 14 diagnosisrelapse sample pairs. This latter finding confirms the comparative microarray expression data that revealed up-regulation of DEFA1-3 at time of relapse. Apart from the observed up-

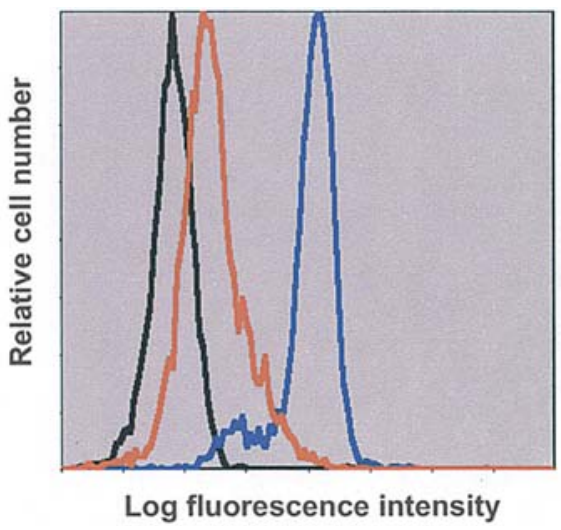

Figure 2. Representative example of flow cytometry evaluation of $\alpha$ defensin 1-3 expression using indirect fluorescence labelling with mAb specific for HNP1-3 (Biogenesis Ltd., catalog no. 2590-5008) and FITCconjugated goat anti-mouse (Immunotech, catalog no. 0819). The blast cells were identified using immunological gate CD45, see Basso et al (7). The histogram was filtered for expression of $\alpha$-defensin1-3 in blast cells. Black, isotype control; red, $\alpha$-defensin1-3 at diagnosis; and blue, $\alpha$-defensin 1-3 expression at relapse.

regulation of DEFA1-3 expression between diagnosis and relapse of the same patient, DEFAl-3 expression levels at diagnosis are highly variable among patients. Interestingly, patients with different clinical outcomes show differences in DEFA1-3 expression levels (Table II, Diagnosis DEFA1-3/ GUS). Of 14 sample pairs, five belonged to patients who had had early relapse, i.e. within 18 months after diagnosis (Table I). Four out of five early relapse samples (Table II, patient no. 6, 44, 32 and 5) at diagnosis showed expression levels of DEFAI-3 that were significantly higher as compared to those of control patients maintaining a state of CR. In four samples of early relapsed patients, DEFAl-3 expression levels were not clearly up-regulated at relapse $(\mathrm{R} / \mathrm{D}$ ratio $\leq 1.58)$, suggesting that up-regulation is not therapy induced, but rather that relative high DEFA1-3 expression levels correlate with a poor response to chemotherapy, resulting in early relapse.

A small proportion of pediatric patients with ALL have refractory leukemia, defined as absence of CR on day 35 after diagnosis (i.e. at the end of the first phase of induction therapy). Samples at diagnosis from 5 of these refractory patients (patient no. 22-26, Tables I and II) were also collected and analysed by RQ-PCR. All five samples exhibited high levels of DEFA1-3 expression.

A group of 19 patients maintaining continuous CR were used as reference of DEFA1-3 expression in good responders to therapy. As shown in Fig. 1, expression of DEFAl-3 was significantly higher $(\mathrm{p}=0.03)$ in refractory patient samples as compared to the control group. DEFA1-3 expression was also higher $(\mathrm{p}=0.03)$ in refractory patients than in the samples taken at diagnosis of late relapsing patients, whereas DEFA1-3 expression levels at diagnosis were not significantly different between early relapsing patients and refractory patients (Fig. 1). These data suggest that high DEFA1-3 expression at diagnosis is predictive of therapy failure, either as resistance to therapy or early relapse.

$\alpha$-defensins are known to be highly expressed in granulocytes and monocytes, while their expression in $\mathrm{T}$ - and Blymphocytes is less known $(11,12)$. Two recent microarray 
expression profiling studies of peripheral blood mononuclear cells (PBMCs) (5) and leukemia bone marrow mononuclear cells (BMMCs) (14) reported a high expression of DEFAl-3. These studies pointed out that DEFAl-3 overexpression was associated with overexpression of both myeloperoxidase $(M P O)$ and elastase-2 (ELA2) genes. These latter genes are preferentially transcribed within the most immature granulocytes and it was suggested that congruent overexpression of DEFA1-3, MPO and ELA2 was part of a granulopoiesis signature (13). In our samples, the expression ratios of myeloperoxidase and elastase- 2 in samples obtained at relapse versus those taken at diagnosis are approximately 1 (average ratio of $1.22 \pm 0.48$ and of $1.53 \pm 0.93$, respectively), while overexpression of $D E F A 3$ was prominent (average ratio of $24.27 \pm 30.71$ ), thus strongly suggesting that the DEFAl-3 overexpression we observed was not part of a granulopoiesis signature or greater myeloid cell load. Moreover, by using flow cytometry, which allows the immunological gating of blast cells, we demonstrated that the blast cell population expresses the $\alpha$-defensin 1-3 protein. Importantly, flow cytometry confirmed that expression of $\alpha$-defensin $1-3$ in the blast cell population of 3 late relapsed patients was 10-fold higher at relapse as compared to blast cells at diagnosis (Fig. 2).

The primary role of human defensin peptides has been implicated in the innate defence response towards microbial invasion. Other evidence pointed to a more versatile function; defensins are known to play a role in antigen driven immune response $(3,4)$ and anti-tumour immunity $(5)$, while a function as transcription factors was suggested for pmolar amounts of $\alpha$-defensin1-3 (6).

The results of this study suggest that high levels of DEFA1-3 mRNA and $\alpha$-defensin 1-3 protein expression at relapse are correlated with disease progression and increased malignancy associated with failure of conventional chemotherapy. In accordance with the finding that, in renal carcinoma cells, expression of $\alpha$-defensin1-3 is a frequent marker of malignancy with possible direct influence on tumour proliferation (15), it may be hypothesized that $\alpha$-defensins are involved in disease progression in ALL blast cells, possibly influencing blast cell proliferation and immune recognition.

DEFA1-3 expression analysis shows considerable variation among groups (Fig. 1) but also within groups. The group of samples from late relapsed patients is a clear example of the latter. A retrospective analysis of DEFA1-3 expression in Blineage ALL samples at diagnosis in a larger patient cohort may reveal additional clinical significance of differential DEFA1-3 expression levels. Functional studies aimed at understanding the role of DEFA1-3 in mechanisms of drug resistance are warranted. Cell-line transfection experiments exemplify how DEFA1-3 overexpression has an effect on cell cycle parameters (personal unpublished data). In conclusion, our study confirms that focussed microarray expression analysis in matched diagnosis-relapse sample pairs studies can reveal new potential markers of leukemia.

\section{Acknowledgements}

This study was supported by Fondazione Città della Speranza, CNR, MURST ex. 40 and $60 \%$, and FIRB grants: RBNE01TZZ8 and RBAU01935A.

\section{References}

1. Gaynon PS, Qu RP, Chappell RJ, Willoughby ML, Tubergen DG, Steinherz PG and Trigg ME: Survival after relapse in childhood acute lymphoblastic leukemia: impact of site and time to first relapse - the Children's Cancer Group Experience. Cancer 8: 1387-1395, 1998.

2. Conter V, Arico M, Valsecchi MG, Basso G, Biondi A, Madon E, Mandelli F, Paolucci G, Pession A, Rizzarari C, Rondelli R, Zanesco L and Masera G: Long-term results of the Italian Association of Pediatric Hematology and Oncology (AIEOP) acute lymphoblastic leukemia studies, 1982-1995. Leukemia 14: 2196-2204, 2000.

3. Ganz T and Lehrer RI: Antimicrobal peptides of vertebrates. Curr Opin Immunol 10: 41-44, 1998.

4. Yang D, Biragyn A, Kwak LW and Oppenheim JJ: Mammalian defensins in immunity: more than just microbocidal. Trends Immunol 23: 291-296, 2002.

5. Biragyn A, Surenhu M, Yang D, Ruffini PA, Haines BA, Klyushnenkova E, Oppenheim JJ and Kwak LW: Mediators of innate immunity that target immature, but not mature, dendritic cells induce antitumor immunity when genetically fused with nonimmunogenetic tumor antigens. J Immunol 167: 6644-6653, 2001.

6. Blomqvist, M, Bergquist J, Westman A, Hakansson K, Hakansson P, Fredman P and Ekman R: Identification of defensins in human lymphocyte nuclei. Eur J Biochem 263: 312-318, 1999.

7. Basso G, Buldini B, De Zen L and Orfao A: New methodologic approaches for immunophenotyping acute leukemias. Haematologica 86: 675-692, 2001.

8. Van Dongen JJ, Macintyre EA, Gabert JA, Delabesse E, Rossi V, Saglio G, Gottardi E, Rambaldi A, Dotti G, Griesinger F, Parreira A, Gameiro P, Diaz MG, Malec M, Langerak AW, San Miguel JF and Biondi A: Standardized RT-PCR analysis of fusion gene transcripts from chromosome aberrations in acute leukemia for detection of minimal residual disease. Report of the BIOMED-1 Concerted Action: investigation of minimal residual disease in acute leukemia. Leukemia 13: 1901-1928, 1999.

9. Germano G, Del Giudice L, Palatron S, Giarin E, Cazzaniga G, Biondi $\mathrm{A}$ and Basso $\mathrm{G}$ : Clonality profile in relapsed precursorB-ALL children by GeneScan and sequencing analyses. Consequences on minimal residual disease monitoring, Leukemia 17: $1573-1582,2003$.

10. Koistinen P: Human peripheral blood and bone marrow cell separation using density gradient centrifugation on Lymphoprep and Percoll in haematological disease. Scand J Clin Lab Invest 47: 709-714, 1987.

11. Agerberth B, Charo J, Werr J, Olsson B, Idali F, Lindbom L, Kiessling R, Jornvall H, Wigzell $\mathrm{H}$ and Gudmundsson GH: The human antimicrobial and chemotactic peptides LL-37 and alphadefensins are expressed by specific lymphocyte and monocyte populations. Blood 96: 3086-3093, 2000.

12. Fang XM, Shu Q, Chen QX, Book M, Sahl HG, Hoeft A and Stuber F: Differential expression of alpha- and beta-defensins in human peripheral blood. Eur J Clin Invest 33: 82-87, 2003.

13. Bennett L, Palucka AK, Arce E, Cantrell V, Borvak J, Banchereau J and Pascual V: Interferon and granulopoiesis signatures in systemic lupus erythematosus blood. J Exp Med 197: 711-723, 2003.

14. Cheok MH, Yang W, Pui CH, Downing JR, Cheng C, Naeve CW, Relling MV and Evans WE: Treatment-specific changes in gene expression discriminate in vivo drug response in human leukemia cells. Nat Genet 34: 85-90, 2003.

15. Muller CA, Markovic-Lipkovski J, Klatt T, Gamper J, Schwarz G, Beck H, Deeg M, Kalbacher H, Widmann S, Wessels JT, Becker V, Muller GA and Flad T: Human alpha-defensins HNPs-1, -2 and -3 in renal cell carcinoma: influences on tumor cell proliferation. Am J Pathol 160: 1311-1324, 2002.

16. Van der Does-van den Berg A, Bartram CR, Basso G, Benoit YC, Biondi A, Debatin KM, Haas OA, Harbott J, Kamps WA and Koller U: Minimal requirements for the diagnosis, classification and evaluation of the treatment of childhood acute lymphoblastic leukemia (ALL) in the 'BFM Family' Cooperative Group. Med Pediatr Oncol 20: 497-505, 1992. 